\title{
An Update on Helicobacter pylori as the Cause of Gastric Cancer
}

\author{
Wei Zhang ${ }^{a}$ Hong Lu ${ }^{a}$ David Y. Graham ${ }^{b}$ \\ aDivision of Gastroenterology and Hepatology, Renji Hospital, School of Medicine, \\ Shanghai Jiaotong University, Shanghai Institute of Digestive Disease, Shanghai, China; \\ ${ }^{b}$ Department of Medicine, Michael E. DeBakey VAMC and Baylor College of Medicine, \\ Houston, Tex., USA
}

\section{Key Words}

Gastric cancer · Helicobacter pylori - Pathogenesis - Virulence factors

\begin{abstract}
Background: Gastric cancer is the second most common cause of cancer deaths worldwide. The vast majority of gastric cancers are inflammation-related cancers caused by infection with Helicobacter pylori. H. pylori-induced oxidative stress damages DNA, resulting in genetic instability. In addition, $H$. pylori itself can cause DNA damage and epigenetic changes that trigger genetic instability and neoplastic transformation. Summary: H. pylori strain-specific components act in combination with host factors and environmental and dietary factors to greatly enhance the inflammatory response and thus the cancer risk. Variations in several key factors, such as the cag pathogenicity island and the VacA protein, can trigger a greater inflammatory response in host cells. Genetic polymorphisms in the host such as in the IL-1 $\beta$ gene, and chromosomes 9p21.3 and 10q23 also play a contributing role. Finally, diet is a major external factor that modulates the risk of gastric cancer. Key Message: The majority of gastric cancers are inflammation-related cancers caused by infection with $\mathrm{H}$. pylori. Eradication of $H$. pylori is important for the prevention and treatment of gastric cancer. Practical Implications: H. pylori eradication results in healing of gastritis and prevention of further $H$. pylori-induced genetic damage. Eradication of $H$. pylori prior to development of atrophic gastritis can prevent the development of gastric cancer. Japan has undertaken a nationwide program to identify and eliminate $H$. pylori, along with surveillance for those who underwent $H$. pylori eradication too late to eliminate cancer risk. Population-wide eradication of H. pylori will result in gastric cancer becoming a vanishingly rare disease. @ 2014 S. Karger AG, Basel
\end{abstract}




\section{Introduction}

Helicobacter pylori is a microaerophilic Gram-negative spiral bacterial pathogen that infects more than $50 \%$ of the word's population [1]. Infection with $H$. pylori is generally acquired in childhood and typically persists for life [2]. As in many chronic infections, most individuals remain asymptomatic with only a small proportion developing clinical disease. H. pylori is considered a pathogen as it universally causes progressive inflammation and gastric mucosal damage. The primary clinical gastrointestinal manifestations of the infection are peptic ulcer disease and gastric cancer $[3,4]$. For more than 100 years it has been recognized that atrophic gastritis was tightly associated with gastric cancer. The discovery of $H$. pylori in the early 1980s identified the cause of chronic gastric mucosal inflammation and thus the underlying cause of gastric cancer $[5,6]$. In 1994, H. pylori was declared a class I (definite) human carcinogen [7] and this classification was confirmed in 2012 [8]. Gastric cancer is now grouped among the inflammation-associated cancers with $H$. pylori as the necessary but insufficient cause.

\section{Gastric Cancer}

Gastric cancer accounts for approximately $10 \%$ of cancers worldwide. It is the fourth most common cancer and the second leading cause of cancer-related deaths. Worldwide there has been a steady decline in both the incidence and mortality of gastric carcinoma [9]. Part of this decline is related to a fall in H. pylori prevalence associated with improved sanitation and standards of living which together reduced the rate of acquisition of the infection. There has also been a decline in the incidence of gastric cancer among infected individuals associated with environmental changes, especially improved diets (i.e., refrigeration replacing salting and smoking for food preservation and improved transportation resulting in fresh produce being available throughout the year).

\section{H. pylori and Gastric Cancer}

Cancer is fundamentally a result of genetic instability. A small proportion of gastric cancers are familial and related to inherited genetic abnormalities that involve alterations in tumor suppressor genes, proto-oncogenes, gatekeeper genes, enzymes, growth factors and membrane or nuclear receptor [10]. Many cancers, including gastric cancer, arise from chronic inflammation [11]. Chronic H. pylori infection causes lifelong acute and chronic gastric inflammation which can result in DNA damage and genetic instability [12]. Recently, it has been recognized that the $H$. pylori organism can also cause genetic instability, including double-stranded DNA breaks and can produce gene activation and silencing via epigenetic pathways [13]. The pathogenesis of $H$. pylori-related genetic instability is complex and as yet incompletely understood with both inflammation-induced reactive oxygen species and reactive nitrogen species playing important roles [14] (fig. 1).

Although $H$. pylori induces lifelong gastric mucosal inflammation, gastric cancer is not a preordained outcome. The clinical manifestations of the infection vary regionally, with important host, $H$. pylori strain, and environmental factors all interacting to determine the outcome for a particular patient and region. Since $H$. pylori is a necessary cause of gastric cancer, a high incidence of gastric cancer requires a high prevalence of H. pylori. However, even among high $H$. pylori prevalence societies such as China, there are strong geographic differences in the incidence of gastric cancer. The most important factor currently recognized 


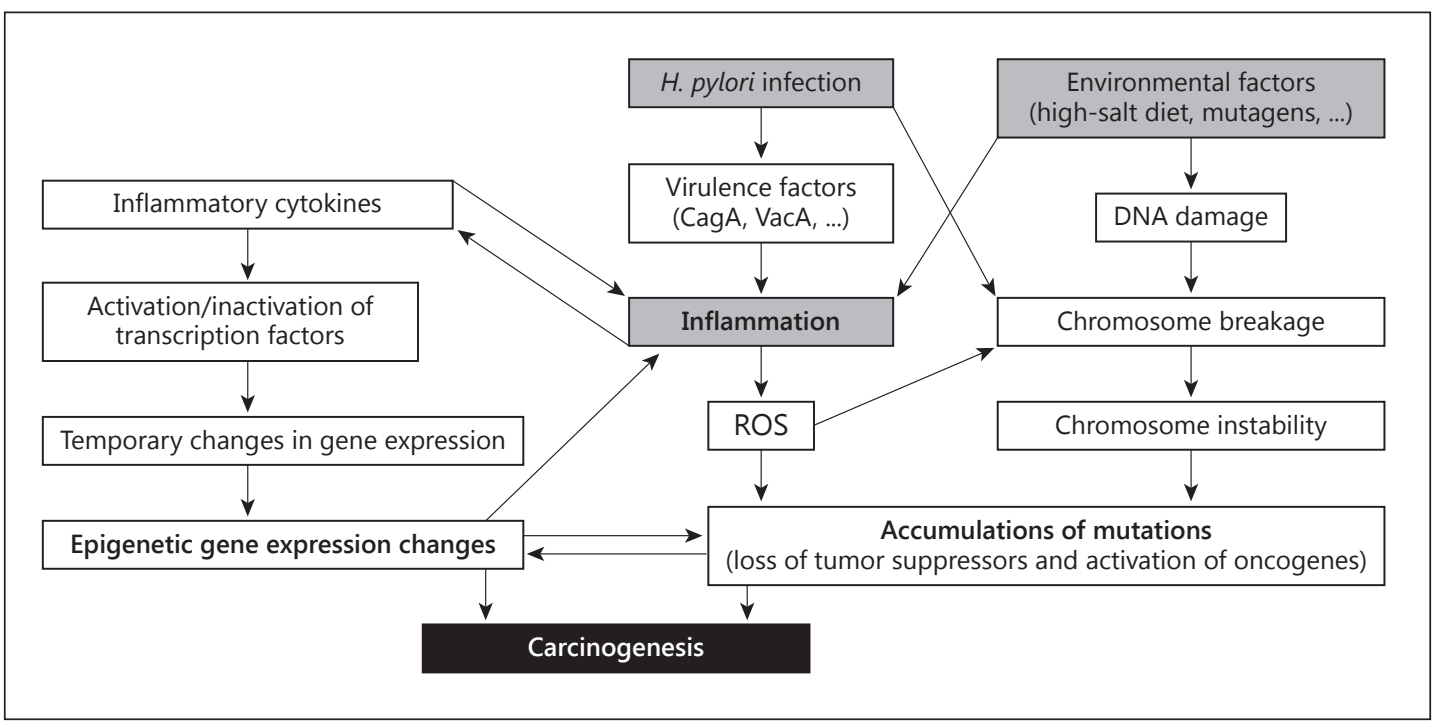

Fig. 1. Schema for development of intestinal-type gastric cancer. From reference [13], with permission. ROS = Reactive oxygen species.

as important in $H$. pylori-environmental interactions resulting in gastric cancer is diet (i.e., cancer risk is highest in regions with seasonal diets where fresh fruits and vegetables are absent for long periods and where salt and smoking are the primary methods of food preservations) [15].

As one might expect, gastric cancer hot spots are often present in mountainous regions and regions with marked seasonal variations where seasonal diets are common, fresh fruits and vegetables are often difficult to obtain and salt is a primary method used for food preservation. Low cancer risk regions are generally ones where fresh fruits and vegetables are available throughout the year [15]. The importance of environmental factors is best illustrated by the fact that even high $H$. pylori-high gastric cancer incidence countries may experience a rapid fall in gastric cancer incidence despite little or no change in $H$. pylori prevalence or H. pylori strain. This is currently best illustrated in Japan, another high gastric cancer incidence country. In Japan there has been a rapid fall in gastric cancer incidence coincident with the diet becoming more western and with refrigeration replacing salt as the primary method of food preservation (fig. 2). This marked change occurred in all age groups, despite no change in host genetics and no change in the most prevalent strain of H. pylori. In addition, immigrants from high gastric cancer incidence countries to low cancer regions, such as from Japan to Hawaii, retain their baseline risk of cancer, whereas their children born in the new environment typically experience a much lower incidence of gastric cancer [17].

\section{Bacterial Factors}

The recognition that $H$. pylori was the cause of gastric cancer led to a great interest in whether there might be bacterial factors that were especially important in determining the outcome of an individual infection. The bacteria possess a variety of factors needed for colonization and long-term residence within the stomach, especially as the stomach changes in response to the infection. The $H$. pylori genome thus encodes products that enhance its ability 


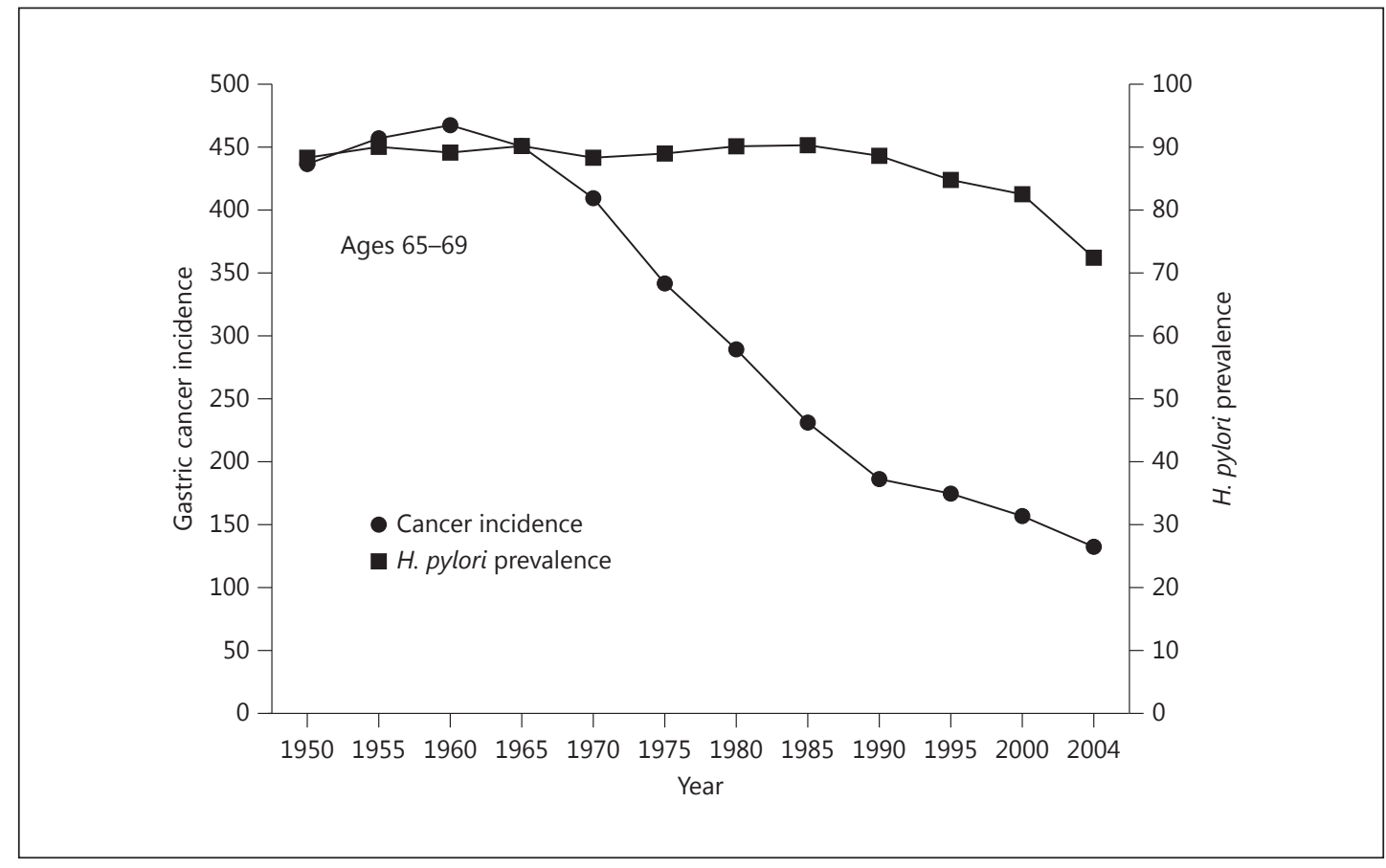

Fig. 2. Changes in the incidence of gastric cancer despite little change in $H$. pylori infection among Japanese men aged 65-69 years during the latter half of the 20th century. Adapted from [16], with permission.

to survive and multiply in an acid environment and to avoid being swept out of the stomach along with the regular emptying of nutrients and other luminal contents. As expected, the organisms are motile and able to move from inhospitable areas to areas where conditions are more favorable and where nutrients are present. $H$. pylori express a variety of adhesions to allow the organisms to adhere to the surface of the stomach such as to not be swept away [18]. Attachment of the organism to cells also influences cell behavior, including making scarce nutrients available directly from host cells [19]. H. pylori can also invade and survive within gastric mucosal surface cells, which provide another niche to avoid the harsh environment of the stomach as well as the host's immune response aimed at elimination of the infection [20].

The histologic hallmark of $H$. pylori infection is the combination of acute and chronic inflammation called acute-on-chronic inflammation. It is thought that mucosal inflammation is especially important in enhancing delivery of nutrients to the organism. Of interest, the gastric mucosa of patients with HIV-AIDS is typically devoid of visible $H$. pylori, consistent with inflammation playing a critical role in $H$. pylori occupation of the stomach [21]. H. pylori can also partially subvert the immune response. For example, $H$. pylori acting through dendritic cells can preferentially induce a T-regulatory cell response versus Th1/Th17 responses $[22,23]$. However, Th1 and Th17 T cell subsets primarily mediate chronic gastritis [24]. In addition to the strong polymorphonuclear and mononuclear cell response, there is also an influx of T-regulatory cells into the mucosa which tend to downregulate the immune response. Moreover, IL-10 produced by T-regulatory cells results in decreased IL-8 production which facilitates bacterial persistence within the host and promotes immune tolerance [25]. Overall H. pylori, like another chronic human pathogen, Mycobacterium tuberculosis, is superbly adapted to life in humans, which is in part responsible for the difficulty in producing an effective vaccine to prevent the infection. 
Since its discovery, scientists have been investigating how $H$. pylori causes inflammation and the relation between putative bacterial virulence factors and the type and severity of the inflammatory response. Efforts have typically focused on putative virulence factors in isolation, and only now are we beginning to see studies aimed at understanding the complex interactions that likely occur. There has been special interest in $H$. pylori outer membrane proteins such as BabA, SabA, OipA, AlpA/B, homB [26-28], the cag pathogenicity island (cagPAI) and the vacuolating cytotoxin VacA [29-31]. It is import to remember that no nonpathogenic $H$. pylori have been discovered (i.e., all $H$. pylori cause gastric mucosal inflammation and have been associated with development of peptic ulcer disease and with gastric cancer). Nonetheless, $H$. pylori pathogenicity as assessed in terms of risk of developing a clinical outcome is best related to a strain's ability to produce inflammation [32-34]. For example, strains considered most pathogenic (i.e., those that possess the cagPAI) are associated with approximately a doubling of the risk of gastric cancer compared to those lacking the cagPAI. One cannot overemphasize that all $H$. pylori are pathogens and that differences between strains are only in the degree of risk and, as a general rule, host and environmental factors associated with an increased inflammatory response to the infection also increase the risk of gastric atrophy and gastric cancer.

\section{Virulence Potential of the Bacterium}

\section{The cag Pathogenicity Island}

The cagPAI is an approximately $40 \mathrm{~kb}$ genomic island consisting of approximately 30 genes $[31,35]$. CagA is a very immunogenic protein encoded by the cagA gene and the presence of CagA antibody is often used as a marker for the presence of an intact cagPAI [36]. The association of CagA-positive strains with an increase in the risk of gastric cancer $[30,37,38]$ has resulted in CagA becoming one of the most widely studied $H$. pylori proteins. However, the majority of studies with CagA have been done in vitro with limited in vitro-in vivo correlations. The cagPAI encodes a type IV secretion system (T4SS) through which CagA is injected into host cells $[36,39]$ where is undergoes tyrosine phosphorylation $\left(\mathrm{CagA}^{\mathrm{PY}}\right)$ at Glu-Pro-IleTyr-Ala (EPIYA) motifs [40]. Recent studies have suggested that strains with cagA with higher numbers of EPIYA-C segments are associated with a higher risk of gastric carcinoma than strains with cagA with one C-type segment $[41,42]$. This finding is also consistent with the pattern of EPIYA segments relating to the ability to induce IL-8. However, there are data that strains with higher numbers of EPIYA repeats have a reduced ability to survive in an acidic environment, suggesting that multiple repeats are an epiphenomenon that occurs after atrophy has developed. Obtaining long-term prospective data from humans regarding changes in the numbers of EPIYA repeats in not practical and would likely be unethical as it would require a delay of therapy in a patient infected with a proven carcinogen. Studies of the numbers of EPIYA repeats in children have examined the hypothesis indirectly and are consistent with the hypothesis that multiple segments are an acquired phenomenon [43].

Another problem with extrapolation of results with experiments with CagA relates to the mechanism of entry of the protein into the cell. Normally, CagA is injected through the plasma membrane. However, a number of critical experiments have used transfection which likely does not mirror the normal processes. Others have studied transgenic animals and have suggested that CagA may have oncogenic properties [44]. The relation of this observation to what happens in natural infection remains unclear. However following injection into the cell and phosphorylation, $\mathrm{CagA}^{\mathrm{PY}}$ can bind to and aberrantly activate SHP2 tyrosine phosphatase which can then deregulate cell proliferation and motility $[41,45,46]$ as well as bind to partitioning-defective 1 (PAR1)/microtubule affinity-regulating kinase (MARK) via the CagA 
multimerization sequence in a tyrosine phosphorylation-independent manner [47]. CagA binding inhibits kinase activity of PAR1b which can result in disruption of epithelial cell polarity [47]. Recently, it has also been reported that CagA is able to induce a transition from polarized epithelial cells (showing cell-cell adhesion) to a more invasive phenotype [48]. Other putative virulence determinants located on the cagPAI such as cagE, cagG, cagH, kcagI, cag $L$ and $\operatorname{cag} M$ are required for $c a g$ PAI-mediated NF- $\mathrm{KB}$ induction. $\operatorname{cag} T$ and $\operatorname{cag} Y$ are required for the formation of a needle-like structure that serves to inject cagA into the host cell [36, 49]. The role of these other factors in the pathogenesis of $H$. pylori-related disease outcomes remains less clear than with CagA. It has also been reported that in some H. pylori strains the cagPAI is split into two separate regions due to the integration of the IS605 insertion sequence [36]. The putative IS605 transposases (tnpA and $\operatorname{tnpB}$ ) can mediate this cagPAI disruption [36] and might also affect the virulence of $H$. pylori [50]. Overall, the exact biological role and clinical relevance of these two determinants remains poorly understood.

While the result with CagA are intriguing, it is important to remember that the presence of CagA is also associated with duodenal ulcer disease which is associated with a non-atrophic gastritis phenotype and a low risk of gastric cancer. Overall, it appears likely that the most important function of CagA is its ability to interact with membrane proteins and trigger a cascade of signal transductions leading to the induction of an enhanced inflammatory response (e.g. through the production of IL-8). In the proper setting enhanced inflammation would tend to favor neoplastic transformation [36, 45, 51], emphasizing again the fundamental role of inflammation in gastric carcinogenesis. To date, few if any of the in vitro observations have been confirmed in vivo. For example, the gastric epithelium of patients with duodenal ulcer retains its characteristics as a 'tight' epithelium with no evidence of significant disruption of cell polarity or any of the other features described in vitro.

$\operatorname{VacA}$

VacA, the $H$. pylori vacuolating cytotoxin, has the ability to induce vacuoles in vitro in infected tissue culture cells [52]. Essentially all strains of $H$. pylori possess a vacA gene, however, there is significant sequence variation among isolates. The greatest diversities are localized to four regions: the signal sequence (s, allele types s1a, s1b, s1c, s2), intermediate (i, allele types i1, i2), mid ( $m$, allele types $m 1, m 2$ ) and autotransporter region $[29,53]$. These variations contribute to differences in the in vitro vacuolating activity of different $H$. pylori strains [29] with $\mathrm{s} 1 / \mathrm{m} 1$ strains being the most cytotoxic. Infection with strains containing type s1, i1 and $\mathrm{m} 1$ forms of $v a c A$ have been associated with a higher risk of gastric cancer compared with $\mathrm{s} 2 / \mathrm{m} 2$ strains $[30,54]$. However, it is important to note that the presence of these so-called more virulent genotypes of VacA is also linked to the co-presence of CagA. Most studies have focused on one factor in isolation rather than on groups or combinations of factors which are highly linked, and this focus has greatly increased the chances of spurious observations.

VacA has been shown to play an important role in the ability of $H$. pylori to survive in host cells and this may be it most important activity [55]. For example, it is possible that the overall inflammatory response may be less with $\mathrm{s} 2$ or $\mathrm{m} 2$ strains if they are less able to enhance the survival of H. pylori within epithelial cells.

There have been numerous in vitro studies of VacA. For example, VacA interacts with numerous host surface receptor molecules in vitro and can trigger various responses, including pore insertion into the cell membrane, modification of endolysosomal functions, cell vacuolation, apoptosis and immune inhibition [56-58]. VacA can also target mitochondria to induce host cell death $[59,60]$. Domanska et al. [60] showed that VacA could form an anion channel to the inner mitochondrial membrane in a p34-dependent manner, whereas Yamasaki et al. [61] reported that VacA indirectly leads to cytochrome $c$ release by activating the 


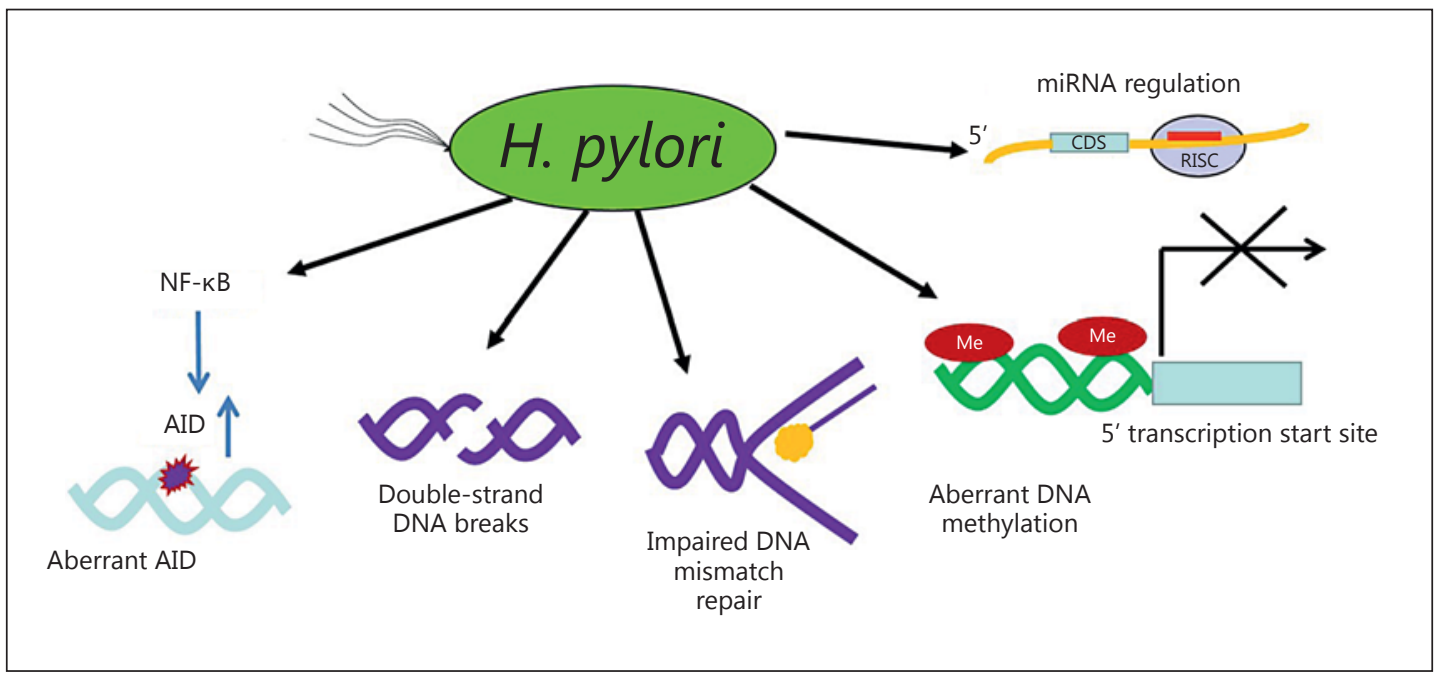

Fig. 3. Mechanisms of H. pylori infection-associated genomic instabilities. Adapted from [63], with permission. AID = Activation-induced cytidine deaminase.

proapoptotic proteins Bax and Bak. $\mathrm{NH}_{4} \mathrm{Cl}$ was able to enhance both VacA-induced vacuolation and Bax activation. Again, in vitro-in vivo correlations are generally lacking such that the results of in vitro studies remain speculative.

\section{Genetic Instabilities}

Genomic instabilities underlie cancer and may result in changes in gene expression; genomic instability is considered one of the necessary steps in carcinogenesis. H. pyloriinduced chronic inflammation and oxidative stress create an environment conducive to DNA damage and tissue injury $[13,62,63]$. DNA damage leads to genetic instability and eventually neoplastic transformation. The Big Blue transgenic mouse is a useful system in which to investigate DNA damage in various tissues, including the stomach. Use of the Big Blue transgenic mouse model confirmed that H. pylori infection was linked to high levels of DNA damage (i.e., AT to GC and GC to TA transversions were increased fourfold following 6 months of infection compared with cells isolated from uninfected control mice) $[64,65]$. In addition to base pair transversions, at least five distinct genetic mechanisms have been identified, including H. pylori infection-associated DNA double-strand breaks, impaired DNA mismatch repair, aberrant activation-induced cytidine deaminase expression (which induces nucleotide alterations involved in DNA mutations), aberrant methylation in gene promoters within the gastric mucosa and aberrant microRNA expression [65] (fig. 3).

\section{Host Factors}

There is a vast literature regarding gene polymorphisms in host interaction that regulate the inflammatory response (i.e., increasing or decreasing the immune response) and its effect of various diseases ranging from periodontal disease to rheumatoid arthritis. Host genes interact with virulence factors throughout the course of the infection and disease pathogenesis [66]. The identification and discrimination of host gene polymorphisms influencing susceptibility in populations with high incidence of gastric cancer has been a major challenge. Genetic polymorphisms in different genes controlling the inflammatory response were related to different abilities to respond to inflammatory stimuli, leading to different degrees of response. Thus, IL-1 $\beta$ gene polymorphisms, specifically $I L-1 \beta-31$ and $I L-1 \beta-511$, result in 
increased IL-1 $\beta$ production, inflammation, hypochlorhydria, gastric atrophy and gastric adenocarcinoma $[67,68]$. Furthermore, recent genome-wide and large-scale gene association studies have focused on genes involved in cell proliferation, differentiation and survival and DNA repair pathways [69]. The chromosome 9p21.3 and 10q23 regions have been identified as genetic susceptibility loci for multiple disease phenotypes including gastric cancer [70, 71]. There are also polymorphisms present in some genes associated with H. pylori infection. The presence of Lewis antigens, which include a group of fucosylated oligosaccharides, can mediate the attachment of $H$. pylori to human gastric mucosa [54]. One study showed that gastric cancer patients had a higher prevalence of $\mathrm{Le}^{\mathrm{a}+\mathrm{b}-}$ phenotype and a lower rate of $\mathrm{Le}^{\mathrm{a}-\mathrm{b}+}$ phenotype $(\mathrm{p}<0.05)$ as compared to non-cancer controls [72]. The TLR-1 and FCGR2A loci have been associated with $H$. pylori seroprevalence and the likelihood that individuals become infected with H. pylori [73].

\section{Dietary Pattern, Nutrition and Other Factors}

Many clinical epidemiological studies have shown the importance of diet in gastric carcinogenesis [74-76]. Risk factors include excessive salt consumption, low consumption of unsaturated fat, fresh vegetables and fruits. A prospective study from a Japanese population suggests that high dietary salt intake ( $>10 \mathrm{~g}$ per day) is a significant risk factor for gastric cancer, and this association was found to be stronger in the presence of $H$. pylori infection with atrophic gastritis [77]. Vitamin C may be a protective factor against dysplasia and gastric cancer as suggested by a prospective study from 3,433 subjects in 1989-1990 performed in Linqu, China, a region with very high rates of gastric cancer [78]. However, after 11 years of follow-up there was no significant associations between multivitamin use and risk for gastric cancer [79]. The high consumption of salted and drained foods is currently often the result of lower economical status and lack of refrigeration. Recent times have seen an increased ability to transport fruits and vegetables and thus a reduction in their availability during specific seasons only. In addition, the use of refrigeration for storage has also been associated with a decrease in gastric cancer incidence in developed countries. In developing countries poor food processing and preparation are still major problems and are associated with a higher gastric cancer incidence [80, 81].

\section{Conclusions}

It is now recognized that $H$. pylori causes at least $95 \%$ of all gastric cancers [63]. The lifetime risk of gastric cancer varies among populations, with a high prevalence of gastric cancer ranging from 1 to approximately 20\%. Gastric cancer is an inflammation-associated cancer, and in addition to the inflammation, the $H$. pylori organism itself can directly cause genetic instability. The gastric cancer risk increases in proportion to the extent and severity of atrophic gastritis [65]. Cure of $H$. pylori prior to development of atrophic gastritis will essentially prevent the development of gastric cancer. H. pylori eradication after that time reduces the incidence of cancer but does not entirely prevent it [63]. H. pylori-induced gastric damage is progressive and the rate is unpredictable, such that $H$. pylori eradication is the only method to ensure cancer prevention or a reduction in gastric cancer risk. Japan has undertaken a country-wide program to find and eliminate $H$. pylori along with surveillance for those who have atrophic gastritis at the time of $H$. pylori eradication, to reduce cancer mortality for those in whom $H$. pylori eradication was done too late to eliminate the risk [82]. Populationwide eradication of $H$. pylori will result in gastric cancer becoming a vanishingly rare disease. When more countries follow Japan's lead and embark on a H. pylori eradication program, gastric cancer will become a rare disease. 


\section{Acknowledgements}

Dr. Graham is supported in part by the Office of Research and Development Medical Research Service Department of Veterans Affairs, Public Health Service grants R01 DK062813 and DK56338 which fund the Texas Medical Center Digestive Diseases Center. The contents are solely the responsibility of the authors and do not necessarily represent the official views of the VA or NIH.

\section{Disclosure Statement}

Dr. Graham is an unpaid consultant for Novartis in relation to vaccine development for treatment or prevention of H. pylori infection. He is a paid consultant for RedHill Biopharma regarding novel H. pylori therapies and has received research support for culture of H. pylori. He is a consultant for Otsuka Pharmaceuticals regarding diagnostic breath testing. He has received royalties from Baylor College of Medicine patents covering materials related to ${ }^{13} \mathrm{C}$-urea breath test.

\section{References}

1 Williams MP, Pounder RE: Helicobacter pylori: from the benign to the malignant. Am J Gastroenterol 1999; 94(11 suppl):S11-S16.

-2 Kusters JG, van Vliet AH, Kuipers EJ: Pathogenesis of Helicobacter pylori infection. Clin Microbiol Rev 2006;19: 449-490.

-3 Peek RM Jr, Blaser MJ: Helicobacter pylori and gastrointestinal tract adenocarcinomas. Nat Rev Cancer 2002; 2:28-37.

4 Salama NR, Hartung ML, Muller A: Life in the human stomach: persistence strategies of the bacterial pathogen Helicobacter pylori. Nat Rev Microbiol 2013;11:385-399.

$\rightarrow 5$ Uemura N, Okamoto S, Yamamoto S, Matsumura N, Yamaguchi S, et al: Helicobacter pylori infection and the development of gastric cancer. N Engl J Med 2001;345:784-789.

6 Forman D, Newell DG, Fullerton F, Yarnell JW, Stacey AR, et al: Association between infection with Helicobacter pylori and risk of gastric cancer: evidence from a prospective investigation. BMJ 1991;302:1302-1305.

7 World Health Organization/International Agency for Research on Cancer: IARC Monographs on the Evaluation of Carcinogenic Risks to Humans. Vol 61: Schistosomes, Liver Flukes and Helicobacter pylori. Lyon, International Agency for Research on Cancer, 1994.

8 Helicobacter pylori. Biologic Agents: A Review of Human Carcinogens, vol 100B. Lyon, International Agency for Research on Cancer, 2012, pp 385-435.

9 Parkin DM, Bray F, Ferlay J, Pisani P: Global cancer statistics, 2002. CA Cancer J Clin 2005;55:74-108.

10 Lynch HT, Grady W, Suriano G, Huntsman D: Gastric cancer: new genetic developments. J Surg Oncol 2005;90: 114-133; discussion 133.

11 Coussens LM, Werb Z: Inflammation and cancer. Nature 2002;420:860-867.

12 Ernst PB, Gold BD: The disease spectrum of Helicobacter pylori: the immunopathogenesis of gastroduodenal ulcer and gastric cancer. Annu Rev Microbiol 2000;54:615-640.

13 Hanada K, Graham DY: Helicobacter pylori and the molecular pathogenesis of intestinal-type gastric carcinoma. Expert Rev Anticancer Ther 2014, Epub ahead of print.

14 Kuper H, Adami HO, Trichopoulos D: Infections as a major preventable cause of human cancer. J Intern Med 2000;248:171-183.

15 Graham DY: Helicobacter pylori infection in the pathogenesis of duodenal ulcer and gastric cancer: a model. Gastroenterology 1997;113:1983-1991.

-16 Graham DY, Lu H, Yamaoka Y: African, Asian or Indian enigma, the East Asian Helicobacter pylori: facts or medical myths. J Dig Dis 2009;10:77-84.

17 Maskarinec G, Noh JJ: The effect of migration on cancer incidence among Japanese in Hawaii. Ethn Dis 2004; 14:431-439.

18 Evans DJ Jr, Evans DG: Helicobacter pylori adhesins: review and perspectives. Helicobacter 2000;5:183-195.

$\checkmark 19$ Boyanova L: Role of Helicobacter pylori virulence factors for iron acquisition from gastric epithelial cells of the host and impact on bacterial colonization. Future Microbiol 2011;6:843-846.

20 Deen NS, Huang SJ, Gong L, Kwok T, Devenish RJ: The impact of autophagic processes on the intracellular fate of Helicobacter pylori: more tricks from an enigmatic pathogen? Autophagy 2013;9:639-652.

-21 Nevin DT, Morgan CJ, Graham DY, Genta RM: Helicobacter pylori gastritis in HIV-infected patients: a review. Helicobacter 2014, Epub ahead of print.

22 Kao JY, Zhang M, Miller MJ, Mills JC, Wang B, et al: Helicobacter pylori immune escape is mediated by dendritic cell-induced Treg skewing and Th17 suppression in mice. Gastroenterology 2010;138:1046-1054. 
23 Wang YH, Gorvel JP, Chu YT, Wu JJ, Lei HY: Helicobacter pylori impairs murine dendritic cell responses to infection. PLoS One 2010;5:e10844.

24 Eaton KA, Mefford M, Thevenot T: The role of T cell subsets and cytokines in the pathogenesis of Helicobacter pylori gastritis in mice. J Immunol 2001;166:7456-7461.

25 Robinson K, Kenefeck R, Pidgeon EL, Shakib S, Patel S, et al: Helicobacter pylori-induced peptic ulcer disease is associated with inadequate regulatory T cell responses. Gut 2008;57:1375-1385.

26 Jung SW, Sugimoto M, Graham DY, Yamaoka Y: homB status of Helicobacter pylori as a novel marker to distinguish gastric cancer from duodenal ulcer. J Clin Microbiol 2009;47:3241-3245.

27 Mahdavi J, Sonden B, Hurtig M, Olfat FO, Forsberg L, et al: Helicobacter pylori SabA adhesin in persistent infection and chronic inflammation. Science 2002;297:573-578.

28 Odenbreit S, Swoboda K, Barwig I, Ruhl S, Boren T, et al: Outer membrane protein expression profile in Helicobacter pylori clinical isolates. Infect Immun 2009;77:3782-3790.

29 Atherton JC, Cao P, Peek RM Jr, Tummuru MK, et al: Mosaicism in vacuolating cytotoxin alleles of Helicobacter pylori. Association of specific vacA types with cytotoxin production and peptic ulceration. J Biol Chem 1995; 270:17771-17777.

-30 Basso D, Zambon CF, Letley DP, Stranges A, Marchet A, et al: Clinical relevance of Helicobacter pylori cagA and vacA gene polymorphisms. Gastroenterology 2008;135:91-99.

-31 Censini S, Lange C, Xiang Z, Crabtree JE, Ghiara P, et al: cag, a pathogenicity island of Helicobacter pylori, encodes type I-specific and disease-associated virulence factors. Proc Natl Acad Sci U S A 1996;93:1464814653.

-32 Palli D, Masala G, Del Giudice G, Plebani M, Basso D, et al: CagA+ Helicobacter pylori infection and gastric cancer risk in the EPIC-EURGAST study. Int J Cancer 2007;120:859-867.

-33 Plummer M, van Doorn LJ, Franceschi S, Kleter B, Canzian F, et al: Helicobacter pylori cytotoxin-associated genotype and gastric precancerous lesions. J Natl Cancer Inst 2007;99:1328-1334.

34 Queiroz DM, Mendes EN, Rocha GA, Oliveira AM, Oliveira CA, et al: cagA-positive Helicobacter pylori and risk for developing gastric carcinoma in Brazil. Int J Cancer 1998;78:135-139.

-35 Akopyants NS, Clifton SW, Kersulyte D, Crabtree JE, Youree BE, et al: Analyses of the cag pathogenicity island of Helicobacter pylori. Mol Microbiol 1998;28:37-53.

-36 Hatakeyama M: Helicobacter pylori CagA - a bacterial intruder conspiring gastric carcinogenesis. Int J Cancer 2006;119:1217-1223.

-37 Blaser MJ, Perez-Perez GI, Kleanthous H, Cover TL, Peek RM, et al: Infection with Helicobacter pylori strains possessing cagA is associated with an increased risk of developing adenocarcinoma of the stomach. Cancer Res 1995;55:2111-2115.

-38 Enroth H, Kraaz W, Engstrand L, Nyren O, Rohan T: Helicobacter pylori strain types and risk of gastric cancer: a case-control study. Cancer Epidemiol Biomarkers Prev 2000;9:981-985.

-39 Fischer W: Assembly and molecular mode of action of the Helicobacter pylori Cag type IV secretion apparatus. FEBS J 2011;278:1203-1212.

40 Backert S, Selbach M: Tyrosine-phosphorylated bacterial effector proteins: the enemies within. Trends Microbiol 2005;13:476-484.

41 Hatakeyama M: Oncogenic mechanisms of the Helicobacter pylori CagA protein. Nat Rev Cancer 2004;4:688694.

-42 Yamaoka Y, Kodama T, Kashima K, Graham DY, Sepulveda AR: Variants of the 3' region of the cagA gene in Helicobacter pylori isolates from patients with different H. pylori-associated diseases. J Clin Microbiol 1998; 36:2258-2263.

43 Yamaoka Y, Reddy R, Graham DY: Helicobacter pylori virulence factor genotypes in children in the United States: clues about genotype and outcome relationships. J Clin Microbiol 2010;48:2550-2551.

-44 Ohnishi N, Yuasa H, Tanaka S, Sawa H, Miura M, et al: Transgenic expression of Helicobacter pylori CagA induces gastrointestinal and hematopoietic neoplasms in mouse. Proc Natl Acad Sci U S A 2008;105:1003-1008.

45 Higashi H, Tsutsumi R, Muto S, Sugiyama T, Azuma T, et al: SHP-2 tyrosine phosphatase as an intracellular target of Helicobacter pylori CagA protein. Science 2002;295:683-686.

46 Higashi H, Nakaya A, Tsutsumi R, Yokoyama K, Fujii Y, et al: Helicobacter pylori CagA induces Ras-independent morphogenetic response through SHP-2 recruitment and activation. J Biol Chem 2004;279:17205-17216.

47 Saadat I, Higashi H, Obuse C, Umeda M, Murata-Kamiya N, et al: Helicobacter pylori CagA targets PAR1/MARK kinase to disrupt epithelial cell polarity. Nature 2007;447:330-333.

48 Bagnoli F, Buti L, Tompkins L, Covacci A, Amieva MR: Helicobacter pylori CagA induces a transition from polarized to invasive phenotypes in MDCK cells. Proc Natl Acad Sci U S A 2005;102:16339-16344.

49 Pachathundikandi SK, Tegtmeyer N, Backert S: Signal transduction of Helicobacter pylori during interaction with host cell protein receptors of epithelial and immune cells. Gut Microbes 2013;4:454-474.

-50 Mattar R, Marques SB, Monteiro Mdo S, Dos Santos AF, Iriya K, et al: Helicobacter pylori cag pathogenicity island genes: clinical relevance for peptic ulcer disease development in Brazil. J Med Microbiol 2007;56 (Pt 1):9-14.

-51 Stein M, Bagnoli F, Halenbeck R, Rappuoli R, Fantl WJ, et al: c-Src/Lyn kinases activate Helicobacter pylori CagA through tyrosine phosphorylation of the EPIYA motifs. Mol Microbiol 2002;43:971-980.

52 Leunk RD, Johnson PT, David BC, Kraft WG, Morgan DR: Cytotoxic activity in broth-culture filtrates of Campylobacter pylori. J Med Microbiol 1988;26:93-99. 
53 Rhead JL, Letley DP, Mohammadi M, Hussein N, Mohagheghi MA, et al: A new Helicobacter pylori vacuolating cytotoxin determinant, the intermediate region, is associated with gastric cancer. Gastroenterology 2007; 133: 926-936.

Figueiredo C, Machado JC, Pharoah P, Seruca R, Sousa S, et al: Helicobacter pylori and interleukin 1 genotyping: an opportunity to identify high-risk individuals for gastric carcinoma. J Natl Cancer Inst 2002;94:1680-1687. Greenfield LK, Jones NL: Modulation of autophagy by Helicobacter pylori and its role in gastric carcinogenesis. Trends Microbiol 2013;21:602-612.

56 Peek RM Jr, Crabtree JE: Helicobacter infection and gastric neoplasia. J Pathol 2006;208:233-248.

-57 Amieva MR, El-Omar EM: Host-bacterial interactions in Helicobacter pylori infection. Gastroenterology 2008; 134:306-323.

58 Wu H, Nakano T, Matsuzaki Y, Ooi Y, Kohno T, et al: A new type of intrabacterial nanotransportation system for VacA in Helicobacter pylori. Med Mol Morphol 2014, Epub ahead of print.

-59 Jain P, Luo ZQ, Blanke SR: Helicobacter pylori vacuolating cytotoxin A (VacA) engages the mitochondrial fission machinery to induce host cell death. Proc Natl Acad Sci U S A 2011;108:16032-16037.

60 Domanska G, Motz C, Meinecke M, Harsman A, Papatheodorou P, et al: Helicobacter pylori VacA toxin/subunit p34: targeting of an anion channel to the inner mitochondrial membrane. PLoS Pathog 2010;6:e1000878.

-61 Yamasaki E, Wada A, Kumatori A, Nakagawa I, Funao J, et al: Helicobacter pylori vacuolating cytotoxin induces activation of the proapoptotic proteins Bax and Bak, leading to cytochrome c release and cell death, independent of vacuolation. J Biol Chem 2006;281:11250-11259.

62 Uehara T, Ma D, Yao Y, Lynch JP, Morales K, et al: H. pylori infection is associated with DNA damage of Lgr5positive epithelial stem cells in the stomach of patients with gastric cancer. Dig Dis Sci 2013;58:140-149.

63 Shiotani A, Cen P, Graham DY: Eradication of gastric cancer is now both possible and practical. Semin Cancer Biol 2013;23:492-501.

64 Jenks PJ, Jeremy AH, Robinson PA, Walker MM, Crabtree JE: Long-term infection with Helicobacter felis and inactivation of the tumour suppressor gene p53 cumulatively enhance the gastric mutation frequency in Big Blue transgenic mice. J Pathol 2003;201:596-602.

-65 Touati E, Michel V, Thiberge JM, Ave P, Huerre M, et al: Deficiency in OGG1 protects against inflammation and mutagenic effects associated with H. pylori infection in mouse. Helicobacter 2006;11:494-505.

$66 \mathrm{He}$ C, Chen M, Liu J, Yuan Y: Host genetic factors respond to pathogenic step-specific virulence factors of Helicobacter pylori in gastric carcinogenesis. Mutat Res Rev Mutat Res 2014;759:14-26.

-67 Sheu BS, Sheu SM, Yang HB, Huang AH, Wu JJ: Host gastric Lewis expression determines the bacterial density of Helicobacter pylori in babA2 genopositive infection. Gut 2003;52:927-932.

68 Sheu MJ, Yang HB, Sheu BS, Cheng HC, Lin CY, et al: Erythrocyte Lewis (A+B-) host phenotype is a factor with familial clustering for increased risk of Helicobacter pylori-related non-cardiac gastric cancer. J Gastroenterol Hepatol 2006;21:1054-1058.

69 Chiurillo MA: Role of gene polymorphisms in gastric cancer and its precursor lesions: current knowledge and perspectives in Latin American countries. World J Gastroenterol 2014;20:4503-4515.

70 Abnet CC, Freedman ND, Hu N, Wang Z, Yu K, et al: A shared susceptibility locus in PLCE1 at 10q23 for gastric adenocarcinoma and esophageal squamous cell carcinoma. Nat Genet 2010;42:764-767.

-71 Gu F, Pfeiffer RM, Bhattacharjee S, Han SS, Taylor PR, et al: Common genetic variants in the 9p21 region and their associations with multiple tumours. Br J Cancer 2013;108:1378-1386.

72 El-Omar EM, Carrington M, Chow WH, McColl KE, Bream JH, et al: Interleukin-1 polymorphisms associated with increased risk of gastric cancer. Nature 2000;404:398-402.

73 Mayerle J, den Hoed CM, Schurmann C, Stolk L, Homuth G, et al: Identification of genetic loci associated with Helicobacter pylori serologic status. JAMA 2013;309:1912-1920.

74 Nemati A, Mahdavi R, Naghizadeh Baghi A: Case-control study of dietary pattern and other risk factors for gastric cancer. Health Promot Perspect 2012;2:20-27.

75 Binici DN, Koca T, Dursun H: Dietary habits, demographical, and socio-economical risk factors of the newly diagnosed gastric cancers in the Eastern Anatolia Region of Turkey: an endemic upper gastrointestinal cancer region. Dig Dis Sci 2009;54:2629-2633.

76 Lazarevic K, Nagorni A, Rancic N, Milutinovic S, Stosic L, et al: Dietary factors and gastric cancer risk: hospitalbased case control study. J BUON 2010;15:89-93.

-77 Shikata K, Kiyohara Y, Kubo M, Yonemoto K, Ninomiya T, et al: A prospective study of dietary salt intake and gastric cancer incidence in a defined Japanese population: the Hisayama study. Int J Cancer 2006;119:196201.

78 You WC, Zhang L, Gail MH, Chang YS, Liu WD, et al: Gastric dysplasia and gastric cancer: Helicobacter pylori, serum vitamin C, and other risk factors. J Natl Cancer Inst 2000;92:1607-1612.

79 Dawsey SP, Hollenbeck A, Schatzkin A, Abnet CC: A prospective study of vitamin and mineral supplement use and the risk of upper gastrointestinal cancers. PLoS One 2014;9:e88774.

-80 La Vecchia C, Negri E, D’Avanzo B, Franceschi S: Electric refrigerator use and gastric cancer risk. Br J Cancer 1990;62:136-137.

81 Cai L, Zheng ZL, Zhang ZF: Risk factors for the gastric cardia cancer: a case-control study in Fujian Province. World J Gastroenterol 2003;9:214-218.

82 Asaka M, Kato M, Sakamoto N: Roadmap to eliminate gastric cancer with Helicobacter pylori eradication and consecutive surveillance in Japan. J Gastroenterol 2014;49:1-8. 